NASA Technical Memorandum 106740

AIAA 94-3981

\title{
Development Status of the NASA 30-cm Ion Thruster and Power Processor
}

James S. Sovey, Thomas W. Haag, John A. Hamley, Maris A. Mantenieks, Michael J. Patterson, Luis R. Pinero, and Vincent K. Rawlin National Aeronautics and Space Administration

Lewis Research Center

Cleveland, Ohio

Michael T. Kussmaul, David H. Manzella, Roger M. Myers, Timothy R. Sarver-Verhey, and George C. Soulas

NYMA, Inc.

Engineering Services Division

Brook Park, Ohio

Kevin C. Cartier

Analex Corporation

Brook Park, Ohio

Prepared for the

29th Intersociety Energy Conversion Engineering Conference cosponsored by IEEE, ACS, AIAA, ANS, ASME, and SAE Monterey, California, August 7-12, 1994

National Aeronautics and

Space Administration 


\title{
DEVELOPMENT STATUS OF THE NASA 30-CM ION THRUSTER AND POWER PROCESSOR
}

\author{
James S. Sovey, Thomas W. Haag, John A. Hamley, Maris A. Mantenieks, \\ Michael J. Patterson, Luis R. Pinero, and Vincent K. Rawlin \\ NASA Lewis Research Center \\ Cleveland, Ohio \\ and \\ Michael T. Kussmaul, David H. Manzella, Roger M. Myers, \\ Timothy R. Sarver-Verhey, and George C. Soulas \\ NYMA \\ Brookpark, Ohio \\ and \\ Kevin C. Cartier \\ Analex Corporation \\ Brookpark, Ohio
}

\begin{abstract}
Xenon ion propulsion systems are being developed by NASA Lewis Research Center and the Jet Propulsion Laboratory to provide flight qualification and validation for planetary and Earth-orbital missions. In the ground-test element of this program, light-weight $(<7 \mathrm{~kg}), 30 \mathrm{~cm}$ diameter ion thrusters have been fabricated, and preliminary design verification tests have been conducted. At $2.3 \mathrm{~kW}$, the thrust, specific impulse, and efficiency were $91 \mathrm{mN}, 3300 \mathrm{~s}$, and 0.65 , respectively. An engineering model thruster is now undergoing a $2000 \mathrm{~h}$ wear-test. A breadboard power processor is being developed to operate from a $80 \mathrm{~V}$ to $120 \mathrm{~V}$ power bus with inverter switching frequencies of $50 \mathrm{kHz}$. The power processor design is a pathfinder and uses only three power supplies. The projected specific mass of a flight unit is about 5 $\mathrm{kg} / \mathrm{kW}$ with an efficiency of 0.92 at the full-power of $2.5 \mathrm{~kW}$. Preliminary integration tests of the neutralizer power supply and the ion thruster have been completed. Fabrication and test of the discharge and beam/accelerator power stages are underway.
\end{abstract}

\section{Introduction}

Ion propulsion systems are being considered for both small-body planetary and Earth-orbital missions. Rendezvous missions with asteroids (such as Ceres or Vesta) and comets (such as Kopff) can be performed with solar electric ion propulsion in shorter $(\sim 2 \mathrm{X})$ times and with more payload than by chemical propulsion systems using the same launch vehicle. ${ }^{(1)}$ The reductions in trip times, typically about 3 to 4 years, imply significant reductions in mission operations costs. Near-term comet or asteroid rendezvous solar electric propulsion (SEP) missions will likely require a power capability of 10 to 14 $\mathrm{kW}$ and use about $250 \mathrm{~kg}$ to $350 \mathrm{~kg}$ of xenon propellant. $^{(1)}$ The propulsion systems will employ 4 to 5 ion thrusters and use three $2.5 \mathrm{~kW}$ power processor units (PPU's) cross-strapped to the thrusters. The thruster life requirement is about $8000 \mathrm{~h}$, and each thruster/PPU will likely be throttled from $2.5 \mathrm{~kW}$ to $0.6 \mathrm{~kW}$. Thrust and specific impulse values at $2.5 \mathrm{~kW}$ are typically $91 \mathrm{mN}$ and 3300 s, respectively. For Earth-orbital applications, ion propulsion can longitudinally reposition geosynchronous satellites more fuel-efficiently than systems using chemical rockets. $^{(2,3)}$ For example, if the bipropellant chemical propulsion system used for North-South stationkeeping (NSSK) of a 10-year, $1800 \mathrm{~kg}$ geosynchronous satellite were replaced with a xenon ion propulsion system (IPS) and additional battery mass, the IPS would provide 15 years of NSSK and two satellite longitudinal reposition moves per year. ${ }^{(3)}$ Earth-orbital spacecraft using IPS for NSSK and repositioning will likely use four thruster/PPU subsystems to accomplish the two functions and provide redundancy. ${ }^{(3)}$ Only two thrusters will be operational at a given time. Repositioning of geosynchronous communications spacecraft involves longitudinal movement within the orbit and is accomplished by thrusting to higher or lower orbits, drifting 
for a given period, and then spiraling back to geosynchronous orbit to obtain the desired phase change. Propulsion times for the combined NSSK and repositioning functions over a 10 to 15 year mission will be in the $4000 \mathrm{~h}$ to $8000 \mathrm{~h}$ range with up to 5000 on-off cycles. $^{(3)}$ Depending on mission requirements and user needs, the thrust subsystem power can be be reduced from the nominal $2.5 \mathrm{~kW}$ level per PPU.

To accomplish the space-flight objectives associated with both small-body planetary and Earth-orbital missions, the NASA Solar Electric Propulsion Technology Applications Readiness (NSTAR) program was organized to demonstrate thrust subsystem life and reliability in ground tests and to provide a flight demonstration to assess interactions with the spacecraft subsystems and the space environment. NASA developed IPS component technologies will be transferred to industrial sources who to develop flight subsystems for a demonstration flight in Earth orbit. Program activities will yield low-risk flight qualified components in forms expected to be used in future planetary and Earth-orbital missions and provide a strong data base to allow Project Managers to baseline IPS for future missions. The overall program schedule shown in Figure 1 generally describes the ground and inspace elements of the NSTAR program. The requirements effort is based on the use of a xenon IPS operating at derated power levels in order to insure thruster wear mechanisms are not a factor in the conduct of the missions. Requirements for future missions are based on the nominal $2.5 \mathrm{~kW}$ thrust subsystems, and thrusters and PPU's can be employed as modular elements to provide the needed total impulse and reliability for a given mission. The ground-test program consists of performance tests, environmental tests, and wear-tests of engineering model ion thrusters and integration tests of breadboard power processors. Design verification includes direct thrust measurements, vibration testing, thermal-vacuum tests, plume diagnostics, and electromagnetic interference (EMI) tests. Planned ion thruster wear evaluations consist of a continuous $2000 \mathrm{~h}$ test, a $4000 \mathrm{~h} / 5000$ cycle test, and finally a $12,000 \mathrm{~h}$ test to provide a $1.5 \mathrm{X}$ demonstration of nominal operating times for small-body planetary missions. The in-space element of the NSTAR program involves obtaining a host spacecraft for the IPS flight demonstration; definition of interfaces; development of flight thrusters, PPU's, a xenon storage/feed system, a diagnostics package; and integration of the subsystems with the host spacecraft. The flight thrusters and PPU's will be developed by industry; the Jet Propulsion Laboratory (JPL) will provide the xenon storage and feed system as well as the diagnostics and will be responsible for the integration effort. The flight demonstration will address key issues such as interactions of the IPS with other spacecraft subsystems. These interactions include EMI, plume impacts, thermal effects, and dynamic interactions on the spacecraft guidance and attitude control system. Additionally, effects of the IPS on science instruments will be assessed by evaluating the IPS induced environment on and about the spacecraft.

This paper will describe the requirements, designs, and development status of NSTAR engineering model ion thrusters and breadboard power processors now being developed in the ground-test program element. Results of thruster performance tests, component tests, vibration tests, and plume diagnostics will be summarized. Power processor converter development and control system status will also be described.

\section{Ion Thruster Development}

To satisfy the requirements for near-term planetary and Earth-orbital propulsion, a $30 \mathrm{~cm}$ diameter xenon ion thruster, throttleable from $2.3 \mathrm{~kW}$ to $0.5 \mathrm{~kW}$, is being developed. A schematic of the ion thruster including the discharge chamber, the discharge hollow cathode, the ion extraction system, and the hollow cathode neutralizer is shown in Figure 2. The thruster will provide a nominal specific impulse of $3300 \mathrm{~s}$, a thrust level of $91 \mathrm{mN}$, and an efficiency of 0.65 at an input power of $2.3 \mathrm{~kW}$. The maximum operational life anticipated is about $8000 \mathrm{~h}^{(1)}$ with ground test demonstration requirements up to $12,000 \mathrm{~h}$. To meet these mission requirements and minimize risk, the xenon ion thruster is operated at derated values of overall power level, ion current density, discharge voltage, and negative accelerator grid voltage to eliminate known life issues and dramatically reduce internal and external erosion rates of electrodes. ${ }^{(4)}$

A series of test programs has been conducted at NASA with laboratory-class $30 \mathrm{~cm}$ ion thrusters to develop a data base for thruster and component performance, component wear-rates, ion extraction capabilities, and reliable hollow cathode operation..$^{(5-8)}$ A functional engineering model thruster (FEMT) was developed to reduce mass, thruster size, parts count, and fabrication costs. ${ }^{(9)}$ Thruster mass has a direct impact on propulsion system elements such as gimbals and structure and an influence on propellant mass, tankage, and propulsion system mass contingency. ${ }^{(10)}$ In the FEMT, mild steel and stainless steel parts were replaced by aluminum components; the number and size of magnets were reduced, and the cylindrical laboratory thruster design was replaced by a conic geometry. The FEMT mass including the basic thruster, gimbal mounts, and wire harness was about $7 \mathrm{~kg}$ excluding the masses of propellant isolators and the wire harness connector.

The light-weight FEMT was tested extensively to quantify overall performance, examine main discharge and neutralizer stability and control, demonstrate throttling capabilities, and 
obtain preliminary data for component wear-rate and lifetime projections. ${ }^{(9)}$ Thruster performance over a power throttling range of $2.3 \mathrm{~kW}$ to $0.55 \mathrm{~kW}$ is shown in Figure 3. Xenon flow to the discharge chamber and the hollow cathodes was stepwise controlled. The power throttling scheme was consistent with a xenon feed system which varies the plenum pressure upstream of flow restrictors as the thruster is throttled. The thruster efficiency changed from 0.65 to 0.59 as the power was decreased from 2.3 $\mathrm{kW}$ to $0.95 \mathrm{~kW}$ and gradually decreased to about 0.50 at $0.55 \mathrm{~kW}$. The discharge power levels and neutralizer flow have a major impact on thrust efficiency at the very low power levels.

The FEMT has undergone diagnostic vibration tests at levels of $0.5 \mathrm{~g}$ and $1 \mathrm{~g}$ at frequencies from $5 \mathrm{~Hz}$ to 2000 $\mathrm{Hz}$. Local structural responses were measured at 19 locations by accelerometers. After review of the vibration test data, design changes to the neutralizer structure and the gimbal pad mounting structure were made. The need to replace aluminum sheet metal parts with titanium was also recognized.

In parallel with the FEMT test program, separate hollow cathode development efforts were conducted, and contamination controls and procedures were developed, discharge ignition tests were performed, handling procedures were defined, electron emitter activation criteria were established, and heater cyclic tests and longterm tests were conducted. ${ }^{(7)}$ Four hollow cathodes were tested for $2000 \mathrm{~h}$ to evaluate active purification of the xenon. Inspection of the electron emitters after the test indicated active purifiers were not required if special feed system and hollow cathode startup procedures were implemented. Three cathode heaters were tested for over 5000 power and thermal cycles in separate component tests. $^{(8)}$ One ongoing lifetest of a hollow cathode assembly has exceeded 10,400 hours of operation with small changes in discharge voltage and cathode temperature. ${ }^{(7)}$ The hollow cathode technology efforts were conducted under the Space Station plasma contactor program $^{(11)}$, and results are directly applicable to the xenon ion thruster development.

Based on the manufacturing and test experiences of the FEMT, an engineering model thruster (EMT) was fabricated. The basic geometry of the FEMT structure was retained in the EMT design except that two loadbearing aluminum shells were replaced by titanium pieces, and the gimbal brackets were stiffened. Significant changes were also made to the mounting structure and the alumina insulators used in the main hollow cathode and neutralizer hollow cathode/keeper electrode assemblies, and a new plasma screen was fabricated using photochemically etched stainless steel. A photograph of the EMT is shown in Figure 4.

The main hollow cathode and neutralizer cathode were assembled using materials and procedures developed by Sarver-Verhey ${ }^{(7)}$ and Soulas. ${ }^{(8)}$ For near-term applications, the main hollow cathode is operated at derated emission currents from $5 \mathrm{~A}$ to $13 \mathrm{~A}$, and the neutralizer cathode total emission current range is from $2.5 \mathrm{~A}$ to $3.8 \mathrm{~A}$.

The discharge chamber magnetic circuit is a ring-cusp design ${ }^{(12)}$ employing three rings of samarium-cobalt magnets with one ring near the cathode assembly, another near the ion optics, and a third ring located at the conic-cylindrical intersection (See Figure 2). The magnets are retained by the spin-formed aluminum and titanium parts.

The ion extraction system is nearly identical to two-grid designs developed for engineering model mercury ion thrusters. ${ }^{(13,14)}$ The positive screen grid and the negative accelerator grid thicknesses are $0.38 \mathrm{~mm}$ and $0.51 \mathrm{~mm}$, with apertures of $1.91 \mathrm{~mm}$ and $1.14 \mathrm{~mm}$, respectively. The open area fraction of the molybdenum screen and accelerator grids are 0.67 and 0.24 , respectively. The screen grid hole pattern is "down-sized" $0.2 \%$ relative to the accelerator grid hole array in order to intentionally misalign the grids and provide ion beam steering which reduces the beam divergence. To provide thermal-mechanical stability, the grids were hydroformed and have a dish-depth of about $23 \mathrm{~mm}$. The nominal cold grid gap was set at about $0.6 \mathrm{~mm}$. Following assembly, a short-term design verification test of the EMT was conducted prior to the start a a $2000 \mathrm{~h}$ wear-test. Results of the preliminary tests indicated that differences in performance of the EMT and the FEMT were within measurement uncertainties. After about $7 \mathrm{~h}$ of operation, electrical and pressure checks indicated electrical breakdowns across one of the two high voltage, low pressure propellant isolators. Additionally, $6.5 \mathrm{~V}$ (peak-to-peak) voltage fluctuations in the neutralizer keeper discharge were observed, and after inspection of the thruster, small propellant leaks were detected in the main cathode low voltage propellant isolator. Based on these findings, the two low pressure propellant isolators will be replaced in subsequent thrusters by one high pressure ( $200 \mathrm{kPa}$ ) isolator with two flow restrictors downstream for the main discharge and the hollow cathode. Isolator brazing processes will be changed. The neutralizer cathode orifice will be decreased to provide a wider range of operation with low voltage fluctuations, and commercial compression fittings will be used in the hollow cathode feed lines. Prior to implementation of these design modications, the EMT mass, including the basic thruster, gimbal mounts, propellant isolators, and the wire harness, was $6.4 \mathrm{~kg}$.

One of the EMT's is now being tested for $2000 \mathrm{~h}$ to obtain electrode wear and erosion data, to characterize thruster longterm performance and stability, and to validate the adequacy of thruster assembly and process documents. The thruster will 
be operated at $2.3 \mathrm{~kW}$ and will provide $1.8 \mathrm{~A}$ of beam ions at $1100 \mathrm{~V}$ which results in specific impulse and thrust levels of $3300 \mathrm{~s}$ and $91 \mathrm{mN}$, respectively. The detailed test requirements and procedures being used were developed by personnel at NASA Lewis Research Center (LeRC) and the Jet Propulsion Laboratory. The $2000 \mathrm{~h}$ test is being conducted in a large space propulsion testbed at LeRC. This testbed has a xenon pumping speed of about $300,000 \mathrm{l} / \mathrm{s}$ using 20 oil diffusion pumps and a 27 $\mathrm{m}^{2}$ helium cryopanel. ${ }^{(15)}$ The background pressure in the vicinity of the thruster is about $0.3 \mathrm{mPa}$.

The ongoing ground test program also includes an extensive set of diagnostics used to assess spacecraft integration issues for the $30 \mathrm{~cm}$ ion thruster. The diagnostics include a $1.2 \mathrm{~m}$ radius rake of ion current density probes which rotates through the thruster plume at axial distances between $1 \mathrm{~m}$ and $3 \mathrm{~m}$ from the thruster. This probe rake and associated data reduction algorithms were evaluated using the FEMT. Typical results, shown in Figure 5, indicate that nearly all of the ion beam was enclosed in a 25 degree half-angle. More detailed assessments are ongoing at LeRC. In addition to the ion current density measurements, an extensive set of contamination and sputtering diagnostics were assembled for use during the $2000 \mathrm{~h}$ wear-test of the EMT. These include quartz, tantalum, and polyimide coupons placed at a variety of distances and angles from the thruster to assess plume impacts. Two quartz crystal microbalances were placed near the thruster exit plane to measure the arrival rate of vacuum facility sputtered effux. Additionally, several quartz and polyimide samples have collimators and shutters designed to eliminate contamination by material sputtered from the vacuum facility walls and to establish the time dependent nature of the plume impacts.

Still remaining in the NSTAR ground test program is the development of two more EMT's and two breadboard power processors. PPU integration and performance tests, thruster vibration tests, plume diagnostics, and EMI characterizations are also planned. The ground test element will culminate in a 4000 hour cyclic test and a 12,000 hour test of an EMT and a breadboard power processor operated at $2.5 \mathrm{~kW}$.

\section{Power Processor Development}

Ion thrusters present many challenging problems for the power processor designer. The basic functions of the power processor include preheating and conditioning the two hollow cathodes, ignition and maintenance of two plasma discharges, energizing the ion acceleration system, properly sequencing the power supplies to initiate thruster operation, flow control of the xenon propellant, and recovery from possible fault conditions. Recent technology efforts to simplify power processors have shown that both the main discharge power supply and the neutralizer power supply could combine cathode heating and plasma generating functions. ${ }^{(16)}$ These "dual use" power stages also provide a discharge starting pulse using energy stored in an output filter inductor. The "dual use" power supply concept was validated using a breadboard neutralizer power supply and the FEMT. In addition to simplifying the PPU, there is a need to provide high efficiency power conversion from the spacecraft bus to the thruster to reduce mass penalties associated with thermal control systems which dissipate the low grade waste heat from the PPU. The overall efficiency of the PPU is determined by the sum of the power losses of the thruster power supplies plus losses attributable to the control system.

The issues of PPU simplification and high efficiency are at the forefront of the NSTAR development effort. The breadboard PPU will operate from a $80 \mathrm{~V}$ to $120 \mathrm{~V} \mathrm{DC}$ power bus and provide $0.6 \mathrm{~kW}$ to $2.5 \mathrm{~kW}$ to the throttleable ion thruster. As a compromise between low mass and high efficiency, a switching frequency of $50 \mathrm{kHz}$ was selected for all power converters in the PPU. A block diagram of the NSTAR breadboard power processor is shown in Figure 6 . The breadboard PPU is a pathfinder, and its topology may be different from the flight hardware which will be developed by an industrial contractor. Three power supplies are used to energize the ion thruster including the discharge, beam/accelerator, and neutralizer supplies. The neutralizer and discharge power supplies provide two constant current outputs each for the cathode heater and the anode electrode. The beam/accelerator power supply provides voltage outputs for the accelerating grids.

The operation of the discharge and neutralizer power supplies can be summarized as follows. The heater output is activated first to heat the cathode. The output is then deenergized and then quickly switched to the anode electrode to initiate the discharge. This approach allows one power stage to drive the two loads with one current regulation control circuit thus reducing parts count and volume required for the power supplies. The maximum power processed by the main discharge is about $450 \mathrm{~W}$; the heaters require $75 \mathrm{~W}$, and the neutralizer keeper discharge requires approximately $40 \mathrm{~W}$. The relatively low power required for these converters led to the selection of a pulse-width-modulated, current mode control, push-pull topology. This concept draws on the heritage of push-pull converter technology developed for $\mathrm{kW}$ class arcjet power supplies. ${ }^{(17)}$ The neutralizer breadboard power supply has been integrated with the FEMT and has demonstrated the cathode heater function, cathode ignition, and ion beam neutralization.

A different approach was taken in the design of the 
beam/accelerator power converter. In this case the positive high voltage, high power output is provided using high efficiency primary side pulse-width-modulated techniques. However, the extremely low power $(\sim 2 \mathrm{~W})$ required for the negative high voltage output allows the accelerator grid voltage to be regulated by a secondary side, linear output stage. A quasi-resonant full-bridge topology was selected for the positive high voltage output which supplies $\sim 1100 \mathrm{VDC}$ at $1.8 \mathrm{~A}$. The selection was based on the need to reduce switching losses with zero voltage switching, without the device stresses or derating required with conventional, resonant converter topologies.

Additional design considerations include the need to recover from short circuits, or faults, between the positive and negative high voltage outputs. Once a fault is detected, a recycle sequence needs to be initiated. The recycle sequence involves turning off the high voltages, reducing the discharge plasma density, applying the high voltages with the negative voltage leading the positive high voltage, and then the discharge current is restored to its nominal operating value. The high voltage recycle process can be accomplished in a few tenths of a second. ${ }^{(18)}$ Since the main discharge anode is referenced to the positive output of the beam/accelerator power supply, high voltage faults can cause rapid reference voltage variations in the discharge power supply, and its circuitry must be suitably protected.

Finally, a PPU controller is being developed to control power supply status during thruster operations, to transmit data to the spacecraft interface, to receive xenon feed system data, and to command feed system valves. Depending upon commands from the spacecraft, the PPU controller will condition the thruster for the first start in space, perform restarts, throttle the power supplies, shutdown the subsystem, and perform fault recovery. The breadboard controller hardware including the microprocessor and all input/output circuitry has been selected. Detailed software development is now being initiated.

The projected packaged mass for the NSTAR power processor, excluding the feed system interface and valve drivers, is $11.9 \mathrm{~kg}$ resulting in a specific mass of about 5 $\mathrm{kg} / \mathrm{kW}$. PPU efficiency is projected to be 0.92 at the 2.5 $\mathrm{kW}$ level, dropping to about 0.83 at the $0.6 \mathrm{~kW}$ minimum power setpoint. The final PPU operating conditions will be mission specific but overall power levels for smallbody planetary missions have been scoped by Kakuda et. al. ${ }^{(1)}$ and the power available per PPU/thruster for Earthorbital missions will likely be in the $1.5 \mathrm{~kW}$ to $2.5 \mathrm{~kW}$ range based on power available to arcjets on communication satellites. $^{(19)}$

\section{Summary}

Xenon ion propulsion systems are being developed by NASA Lewis Research Center and the Jet Propulsion Labloratory to provide flight qualification and validation for planetary and Earth-orbital missions. Once validated, thruster/power processor modules, operating at $2.5 \mathrm{~kW}$ or less, will be used to build propulsion systems consistent with user's requirements. For example, $10 \mathrm{~kW}$ to $14 \mathrm{~kW}$ systems are envisioned for small-body planetary missions that also require thruster power throttling from $2.3 \mathrm{~kW}$ at about $3300 \mathrm{~s}$ specific impulse to $0.55 \mathrm{~kW}$. In-space operational lifetimes, at 2.3 $\mathrm{kW}$, may be as high as $8000 \mathrm{~h}$ for 15 year Earth-orbital missions with many spacecraft repositioning moves. Thirty centimeter diameter xenon thrusters have been developed to a high level of maturity to satisfy near-term requirements for planetary and Earth-space satellites. A functional engineering model thruster has undergone diagnostic vibration tests, performance tests using a thrust-stand, and plume diagnostic tests. These data have been used to define the design of an engineering model thruster (EMT). The first EMT has been assembled and has completed a short-term design verification test. The EMT is now undergoing a $2000 \mathrm{~h}$ wear-test at 2.3 $\mathrm{kW}$ in a test chamber whose pressure is about $0.3 \mathrm{mPa}$.

A breadboard power processor is being developed to operate from a $80 \mathrm{~V}$ to $120 \mathrm{~V}$ power bus and provide $0.55 \mathrm{~kW}$ to 2.3 $\mathrm{kW}$ to the xenon thruster. A $50 \mathrm{kHz}$ switching frequency was selected in a trade aimed at reduced magnetics mass and high efficiency. The breadboard PPU design incorporates three power supplies to provide all thruster functions. Dual-use neutralizer and discharge power supplies each provide outputs for both a heater and an anode electrode. The beam/accelerator supply provides voltage to the ion accelerator grids and also accommodates recovery from high-voltage faults or arcs. The two low voltage power supplies employ a push-pull design while the beam/accelerator stage utilizes a full-bridge topology. The breadboard PPU topology is a pathfinder which will be evaluated by NASA and an industrial contractor. A breadboard controller, using a microprocessor, completes the PPU assembly and provides for start-up, throttling, shutdown, fault recovery, and supplies subsystem data. The low voltage power supplies have been fabricated and are now undergoing functional tests on resistive loads and ion thrusters. The high-voltage supply is now being assembled. The breadboard power supplies will be separately integrated with an ion thruster prior to final tests with a fullup breadboard PPU. Projected specific mass of a flight packaged PPU is about $5 \mathrm{~kg} / \mathrm{kW}$ at an input power of $2.5 \mathrm{~kW}$ and an efficiency of 0.92 .

Products of the NSTAR ground-test program are the development, integration, and tests of three engineering model ion thrusters and two breadboard power processors. Thruster 
wear-tests of $2000 \mathrm{~h}, 4000 \mathrm{~h}$, and $12,000 \mathrm{~h}$ will verify the thruster design, establish wear rates, symptoms of early and random failures, and demonstrate compatibility of the ion thruster and PPU with user requirements.

\section{Acknowledgements}

The authors would like to acknowledge the valuable fabrication and test support provided by LeRC's Test Installations Division as well as the support from researchers at Colorado State University and Ohio State University. The support from NSTAR team members at JPL, including Michael Marcucci, John Brophy, and Stan Krauthamer, is gratefully acknowledged. The mission design and requirements definition work provided by JPL and LeRC groups whose leaders are Joel Sercel and John Riehl, respectively, is gratefully acknowledged.

\section{References}

'Kakuda, R., Sercel, J., and Lee, W., "Small Body Rendezvous Mission Using Solar Electric Ion Propulsion: Low Cost Mission Approach and Technology Requirements," IAA Paper L-0710, April 1994.

${ }^{2} J a n s o n$, S. W., "The On-Orbit Role of Electric Propulsion," AIAA Paper 93-2220, June 1993.

${ }^{3}$ Hack, K. J. and Oleson, S. R., Personal Communication, NASA Lewis Research Center, Cleveland, OH, March 1994.

${ }^{4}$ Patterson, M. J. and Foster, J. E., "Performance and Optimization of a "Derated" Ion Thruster for Auxiliary Propulsion," AIAA Paper 91-2350, June 1991.

${ }^{5}$ Patterson, M. J., "Low-I $\mathrm{I}_{\mathrm{sp}}$ Derated Ion Thruster Operation," AIAA Paper 92-3203, July 1992.
${ }^{6}$ Rawlin, V. K., "Erosion Characteristics of Two-Grid Ion Accelerating Systems," IEPC Paper 93-175,

September 1993.

${ }^{7}$ Sarver-Verhey, T. R., "Continuing Life Test of a Xenon Hollow Cathode for a Space Plasma Contactor," AIAA Paper 94-3312, June 1994.

${ }^{8}$ Soulas, G. C., "Hollow Cathode Heater Development for the Space Station Plasma Contactor," NASA CR-191131, October 1993.

${ }^{9}$ Patterson, M. J., Haag, T. W., and Hovan, S. A., "Performance of the NASA $30 \mathrm{~cm}$ Ion Thruster," IEPC Paper 93-108, September 1993.

${ }^{10}$ Rawlin, V. K. and Majcher, G. A., "Mass Comparisons of Electric Propulsion Systems for NSSK of Geosynchronous Spacecraft," AIAA Paper 91-2347, June 1991.

${ }^{11}$ Patterson, M. J., et. al., "Plasma Contactor Development for Space Station," IEPC Paper 93-246, September 1993.

${ }^{12}$ Sovey, J. S., "Improved Ion Containment Using a RingCusp Ion Thruster," Journal of Spacecraft and Rockets, Vol. 21, September-October, 1984, pp. 488-495.

${ }^{13}$ Anon., "30-Centimeter Ion Thrust Subsystem Design Manual," NASA TM 79191, 1979.

${ }^{14}$ Rawlin, V. K., "Erosion Characteristics of Two-Grid Ion Accelerating Systems," IEPC Paper 93-175, September 1993.

${ }^{15}$ Grisnik, S. P. and Parkes, J. E., "A Large, High Vacuum, High Pumping Speed Space Simulation Chamber for Electric Propulsion," IEPC Paper 93-151, September 1993.

${ }^{16}$ Rawlin, V. K., Pinero, L. R., and Hamley, J. A., "Simplified Power Processing for Inert Gas Ion Thrusters," AIAA Paper 93-2397, June 1993.

${ }^{17}$ Hamley, J. A. and Hill, G. M., "Power Electronics for Low Power Arcjets," AIAA Paper 91-1991, June 1991.

${ }^{18}$ Pinero, L. R., Patterson, M. J., and Satterwhite, V. E., "Power Console Development for NASA's Electric Propulsion Outreach Program," IEPC Paper 93-250, September 1993.

${ }^{19}$ Smith, W. W., et. al., "Low Power Hydrazine Arcjet Flight Qualification," IEPC Paper 91-148, October 1991. 


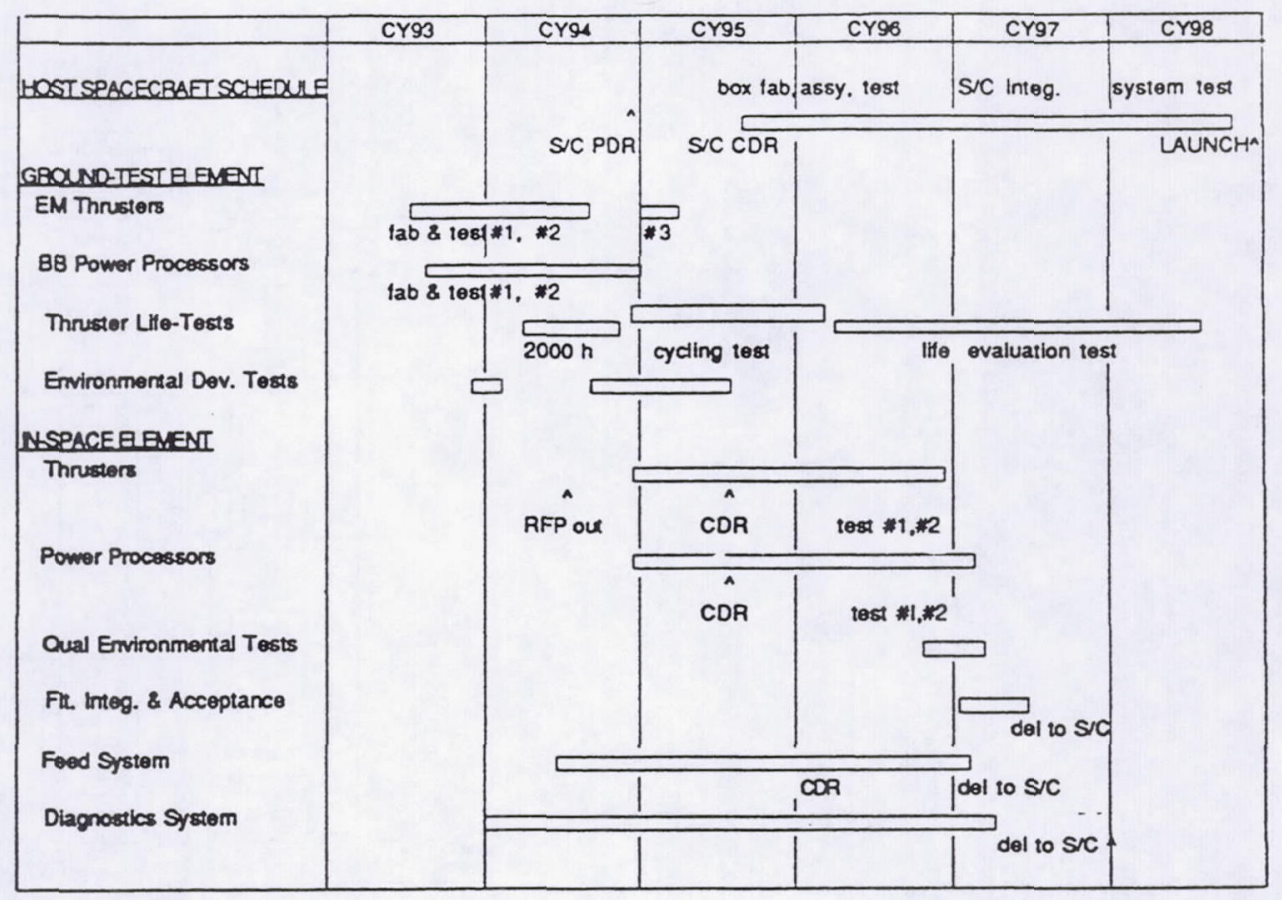

Fig. 1 NSTAR overall schedule.

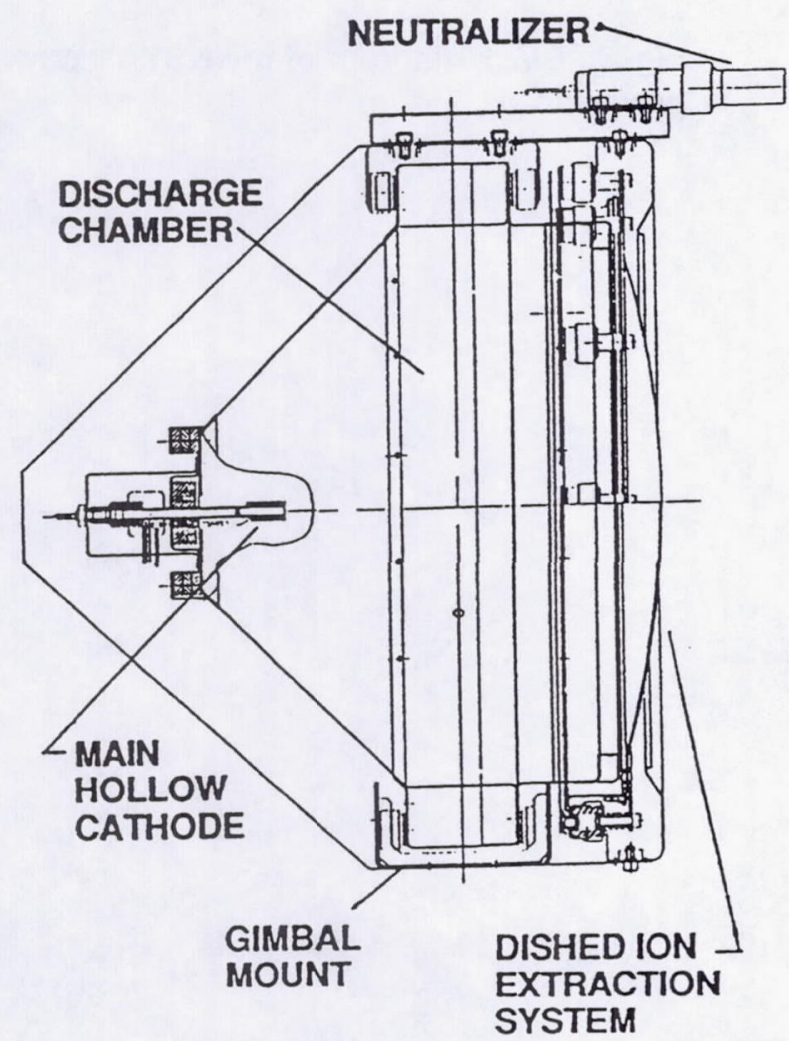

Fig. 2 Schematic of the NASA $30 \mathrm{~cm}$ diameter Ion thruster.

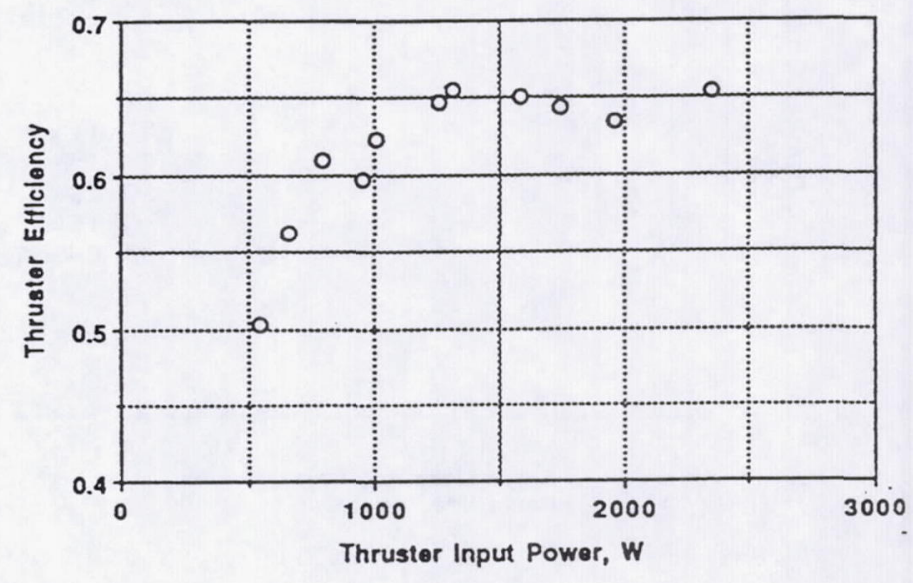

Fig. 3 Upper bound of throttling performance of the FEMT. 


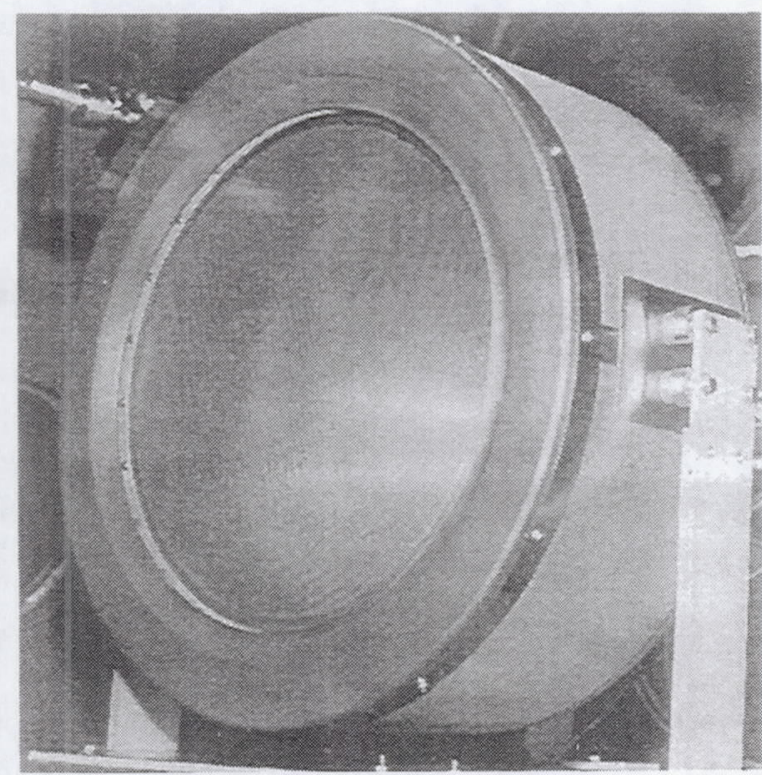

Fig. 4 Photograph of the engineering model ion thruster.

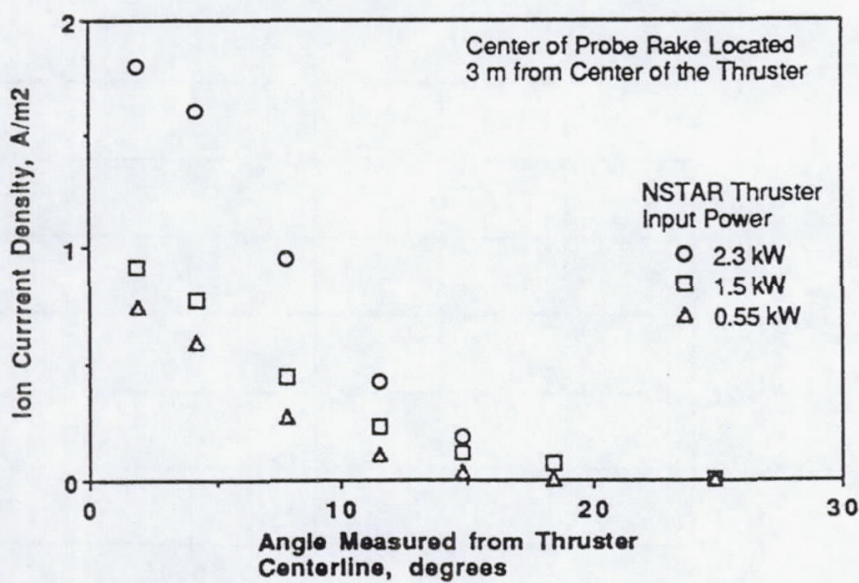

Fig. 5 Ion current density profiles $3 \mathrm{~m}$ downstream of the FEMT.

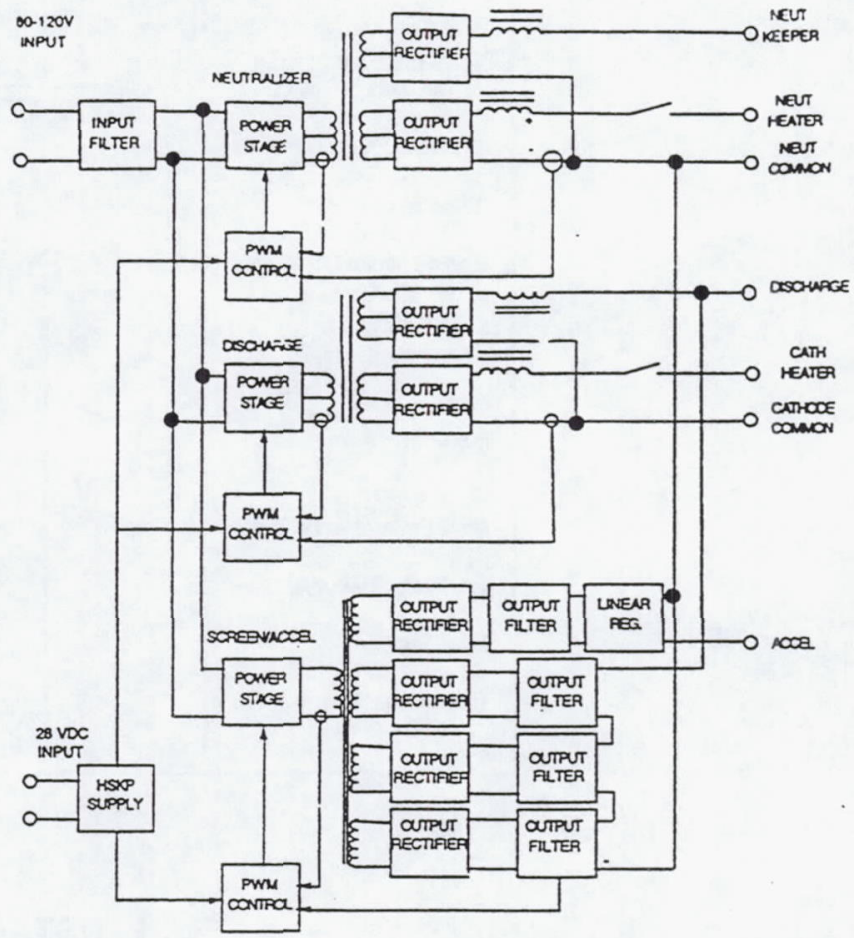

Fig. 6 Block diagram of the NSTAR power processor. 
Public reporting burden for this collection of information is estimated to average 1 hour per response, including the time for reviewing instructions, searching existing data sources, gathering and maintaining the data needed, and completing and reviewing the collection of information. Send comments regarding this burden estimate or any other aspect of this collection of information, including suggestions for reducing this burden, to Washington Headquarters Services, Directorate for Information Operations and Reports, 1215 Jefferson Davis Highway, Suite 1204, Arlington, VA 22202-4302, and to the Office of Management and Budget, Paperwork Reduction Project (0704-0188), Washington, DC 20503.
1. AGENCY USE ONLY (Leave blank)
2. REPORT DATE
September, 1994
3. REPORT TYPE AND DATES COVERED
Technical Memorandum

4. TITLE AND SUBTITLE

5. FUNDING NUMBERS

Development Status of the NASA $30-\mathrm{cm}$ Ion Thruster and Power Processor

6. AUTHOR(S)

James S. Sovey, Thomas W. Haag, John A. Hamley, Maris A. Mantenieks,

Michael J. Patterson, Luis R. Pinero, Vincent K. Rawlin, Michael T. Kussmaul,

David H.Manzella, Roger M. Myers, Timothy R. Sarver-Verhey, George C. Soulas, and

Kevin C. Cartier

7. PERFORMING ORGANIZATION NAME(S) AND ADDRESS(ES)

National Aeronautics and Space Administration

Lewis Research Center

Cleveland, Ohio 44135-3191

WU-232-02-02

\section{SPONSORING/MONITORING AGENCY NAME(S) AND ADDRESS(ES)}

National Aeronautics and Space Administration

Washington, D.C. 20546-0001
8. PERFORMING ORGANIZATION REPORT NUMBER

E-9147

10. SPONSORING/MONITORING AGENCY REPORT NUMBER

NASA TM-106740

\section{SUPPLEMENTARY NOTES}

Prepared for the 29th Intersociety Energy Conversion Engineering Conference cosponsored by IEEE, ACS, AIAA, ANS, ASME, and SAE, Monterey, California, August 7-12,1994. James S. Sovey, Thomas W. Haag, John A. Hamley, Maris A. Mantenieks, Michael J. Patterson, Luis R. Pinero, and Vincent K. Rawlin, NASA Lewis Research Center; Michael T. Kussmaul, David H. Manzella, Roger M. Myers, Timothy R. Sarver-Verhey, and George C. Soulas, NYMA, Inc, Engineering Services Division, 2001 Aerospace Parkway, Brook Park, Ohio 44142 ( Work funded by NASA contract NAS3-27186); Kevin C. Cartier, Analex Corporation, 3001 Aerospace Parkway, Brook Park, Ohio 44142 (work funded by NASA contract NAS3-25776). Responsible person, James S. Sovey, organization code 5330, (216) 977-7454.

\section{2a. DISTRIBUTION/AVAILABILITY STATEMENT}

Unclassified -Unlimited

Subject Category 20

\section{2b. DISTRIBUTION CODE}

\section{ABSTRACT (Maximum 200 words)}

Xenon ion propulsion systems are being developed by NASA Lewis Research Center and the Jet Propulsion Laboratory to provide flight qualification and validation for planetary and Earth-orbital missions. In the ground-test element of this program, light-weight ( $<7 \mathrm{~kg}), 30 \mathrm{~cm}$ diameter ion thrusters have been fabricated, and preliminary design verification tests have been conducted. At $2.3 \mathrm{~kW}$, the thrust, specific impulse, and efficiency were $91 \mathrm{mN}, 3300 \mathrm{~s}$, and 0.65 , respectively. An engineering model thruster is now undergoing a $2000 \mathrm{~h}$ wear-test. A breadboard power processor is being developed to operate from a $80 \mathrm{~V}$ to $120 \mathrm{~V}$ power bus with inverter switching frequencies of $50 \mathrm{kHz}$. The power processor design is a pathfinder and uses only three power supplies. The projected specific mass of a flight unit is about $5 \mathrm{~kg} / \mathrm{kW}$ with an efficiency of 0.92 at the full- power of $2.5 \mathrm{~kW}$. Preliminary integration tests of the neutralizer power supply and the ion thruster have been completed. Fabrication and test of the discharge and beam/accelerator power stages are underway.

\section{SUBJECT TERMS}

Electric propulsion; Ion propulsion; Space propulsion; Plasma applications

17. SECURITY CLASSIFICATION OF REPORT Unclassified

18. SECURITY CLASSIFICATION
OF THIS PAGE
Unclassified

19. SECURITY CLASSIFICATION OF ABSTRACT Unclassified 